\title{
Estudo voltamétrico do Fe em soluções de $\mathrm{NaOH}$
}

\author{
Giori, J. G. ${ }^{1}$; Brito, G. A. O. ${ }^{1}$ \\ 1 Departamento de Química e Física, Centro de Ciências Agrárias, Universidade Federal do Espírito \\ Santo, Alegre, ES, Brasil
}

\section{Resumo}

Foram realizados estudos empregando voltametria, com diferentes velocidades de varredura, aos sistemas $\mathrm{Fe} / \mathrm{NaOH} 0,10 \mathrm{molL}^{-1}$ e Fe/NaOH 1,0 molL-1. Para isto, foi realizado o seguinte procedimento: um pré-tratamento envolvendo diversos ciclos com uma etapa potenciostática em potencial catódico seguida de um ciclo voltamétrico (considerada como a medida do experimento), com agitação da solução. Através da carga anódica total calculada a partir dos voltamogramas obtidos, verificou-se alta reprodutibilidade com diferença de carga total menor do que $3 \%$ entre a voltametria considerada como medida e a última voltametria do pré-tratamento. Os voltamogramas considerados como medidas apresentaram a baixas velocidades de varredura um único pico anódico e evoluíam para maiores velocidade para a presença de dois picos anódicos.

Palavras chaves: ferro, hidróxido de sódio, voltametria

\section{Introdução}

O estudo da formação e crescimento de filmes de passivação sobre metais e suas ligas pode ser dividido fundamentalmente em duas grandes linhas [1, 2]: uma que utiliza técnicas de análise de superfície combinadas com técnicas eletroquímicas; outra que realiza estudos cinéticos com técnicas eletroquímicas, considerando modelos propostos na literatura.

No caso específico do ferro e suas ligas, são muitos os estudos utilizando técnicas de análise de superfície combinadas com técnicas eletroquímicas, que tratam da composição, estrutura de fase e processos de formação e crescimento do filme de passivação [3-7]. Tais estudos mostram que todos estes aspectos dos filmes da passivação do ferro e suas ligas dependem de fatores tais como $\mathrm{pH}$, temperatura e condição redox [3], chegando a ocorrer resultados contraditórios.

Também são muitos os estudos de filmes de passivação em ferro e suas ligas, nos quais são utilizadas técnicas eletroquímicas, tendo em conta modelos de crescimento destes filmes propostos pela literatura [1, 8-12]. Não há um consenso na literatura a respeito de qual modelo descreve mais adequadamente a formação e o crescimento de filmes de passivação. Por exemplo, Sato et al. [22] aplicaram o modelo de camada de transição para o estudo sobre o filme de passivação formado sobre Fe em soluções de $\mathrm{H}_{3} \mathrm{PO}_{4}$ ( $\mathrm{pH}$ ácido) e de Borato ( $\mathrm{pH}$ alcalino), em condição potenciostática. Já Amaral et al. [1] aplicaram o modelo Ohmico aos resultados de voltametrias dos sistemas Fe/Borax 0,1 mol L-1 e Fe/NaOH 0,01 mol L-1 + silicato de sódio (500 ppm de $\mathrm{SiO}_{2}$ ). O presente trabalho apresentará resultados do estudo voltamétrico dos sistemas Fe/NaOH 0,10 mol L-1 e Fe/NaOH 1,0 mol $\mathrm{L}^{-1}$, aos quais será aplicado futuramente o modelo ôhmico.

\section{Materiais e Métodos}

O eletrodo de trabalho foi Fe com pureza maior do que 99,9\% em massa, com área eletroativa de $0,28 \mathrm{~cm}^{2}$. Soluções utilizadas: $\mathrm{NaOH} 0,10 \mathrm{~mol} \mathrm{~L}^{-1}$ e Fe/NaOH 1,0 mol $L^{-1}$, desoxigenadas. Eletrodo de referência: $\mathrm{Hg} / \mathrm{HgO} / \mathrm{NaOH}$ 0,10 mol L-1. Contra-eletrodo e eletrodo auxiliar: bastão de grafite. O procedimento para as medidas voltamétricas foi o seguinte. Primeiramente, 0 eletrodo de trabalho era polido com lixa 600. Então era realizado um pré-tratamento: o eletrodo de trabalho era introduzido na solução polarizado catodicamente no potencial $-1,1 \mathrm{~V}$ e permanecia neste potencial por 5 minutos; após esta etapa, realizava-se uma voltametria 
iniciando com uma varredura anódica de $-1,1 \mathrm{~V}$ a 0,80 $\mathrm{V}$, seguida de uma varredura catódica de $0,80 \mathrm{~V}$ a $-1,1$ $\mathrm{V}$; imediatamente depois, o eletrodo de trabalho era catodicamente polarizado em $-1,1 \mathrm{~V}$ por mais cinco minutos; este ciclo, que envolvia a etapa potenciostática, a voltametria e uma nova etapa potenciostática, era repetido dez vezes; o décimo primeiro ciclo era tomado como a medida voltamétrica de interesse. As velocidades de varredura utilizadas foram: 10, 20, 50, 100, 250 e $500 \mathrm{mVs}^{-1}$.

\section{Resultados e Discussão}

$\mathrm{Na}$ Figura 1, estão representados os voltamogramas dos 10 ciclos de estabilização e da medida de interesse para o sistema $\mathrm{Fe} / \mathrm{NaOH} 0,10 \mathrm{molL}^{-1}$ (a) e dos 9 ciclos de estabilização e da medida de interesse para o sistema $\mathrm{Fe} / \mathrm{NaOH}$ 1,0 $\mathrm{molL}^{-1}$ (b) (velocidade de varredura $50 \mathrm{mV} \mathrm{s}^{-1}$ ). Em todos os casos, o voltamograma da medida de interesse não apresentou problemas devido a formação de bolhas de hidrogênio. Além disto, os voltamogramas tenderam a um perfil estacionário. Isto se deveria à estabilização da superfície do metal devido ao pré-tratamento. Ao comparar o penúltimo e o último voltamograma em cada um dos casos representados na Figura 1, verificase que a diferença de carga anódica total destas varreduras é de $3 \%$, mostrando a estabilização da superfície, o que garante a reprodutibilidade das medidas. Estes resultados representam 0 comportamento observado nas demais velocidades para ambos os sistemas.

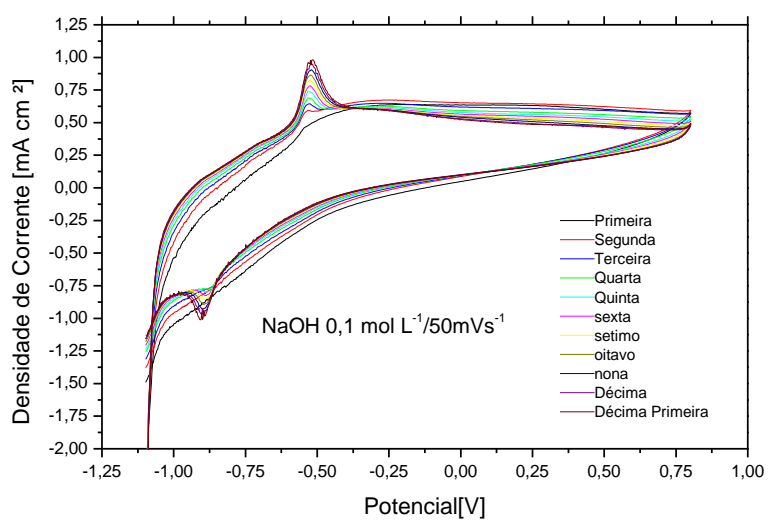

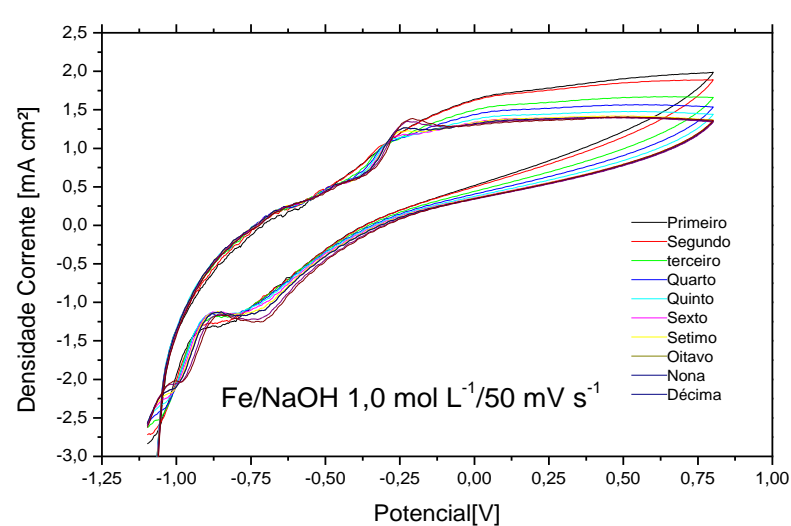

Figura 1: Voltamogramas dos sistemas (a) $\mathrm{Fe} / \mathrm{NaOH} 0,10 \mathrm{~mol} \mathrm{~L}^{-1} \mathrm{e}$ (b) $\mathrm{Fe} / \mathrm{NaOH}$ 1,0 mol L-1. Velocidade de varredura: $50 \mathrm{mVs}^{-1}$.

Nas Figuras 2 e 3, estão representados os voltamogramas das medidas de interesse para os sistemas $\mathrm{Fe} / \mathrm{NaOH} 0,10 \mathrm{~mol} \mathrm{~L}^{-1}$ e $\mathrm{Fe} / \mathrm{NaOH} 1,0 \mathrm{~mol} \mathrm{~L}^{-1}$. Para o sistema $\mathrm{Fe} / \mathrm{NaOH} 0,10 \mathrm{~mol} \mathrm{~L}^{-1}$, nas velocidades de varredura 10, 20, 50 e $100 \mathrm{mV} \mathrm{s}^{-1}$, há a presença de um único pico anódico nos voltamogramas. Já para a velocidade de varredura $250 \mathrm{mV} \mathrm{s}^{-1}$, há dois picos anódicos. Quanto ao sistema Fe/NaOH 1,0 mol L-1, nas velocidades de varredura 10,20 e $50 \mathrm{mV} \mathrm{s}^{-1}$, há um pico anódico no voltamograma. Para este mesmo sistema, nas velocidades 100, 250 e $500 \mathrm{mV} \mathrm{s}^{-1}$, há dois picos anódicos. Para os casos em que o voltamograma apresentou um pico anódico, nos dois sistemas estudados, uma possível interpretação é que esteja associada à formação e crescimento de um filme de $\mathrm{Fe}(\mathrm{OH})_{2}$ [1]. Quanto aos casos em que no voltamograma havia dois picos anódicos, a interpretação do primeiro pico seria a formação e crescimento de um filme de $\mathrm{Fe}(\mathrm{OH})_{2}$ e o segundo pico seria a passagem de $\mathrm{Fe}(\mathrm{OH})_{2}$ a $\alpha-\mathrm{FeOOH}$ [1].

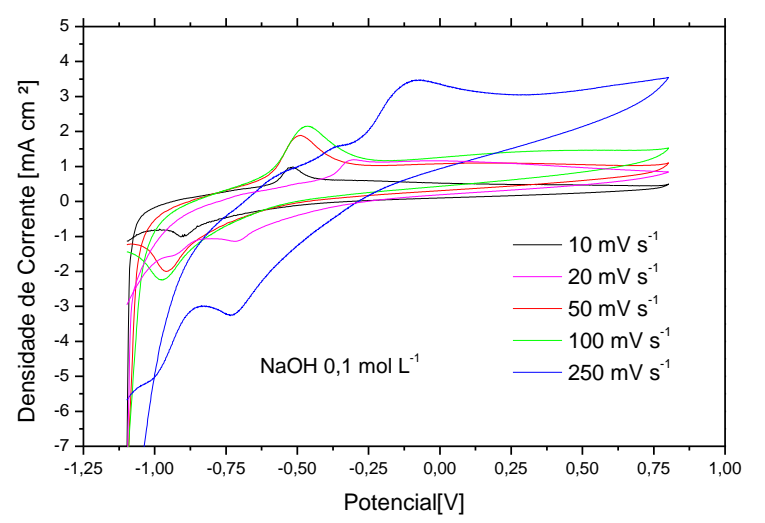

Figura 2: Voltamogramas para diferentes velocidade de varredura do sistema $\mathrm{Fe} / \mathrm{NaOH} 0,10 \mathrm{~mol} \mathrm{~L}^{-1}$. 


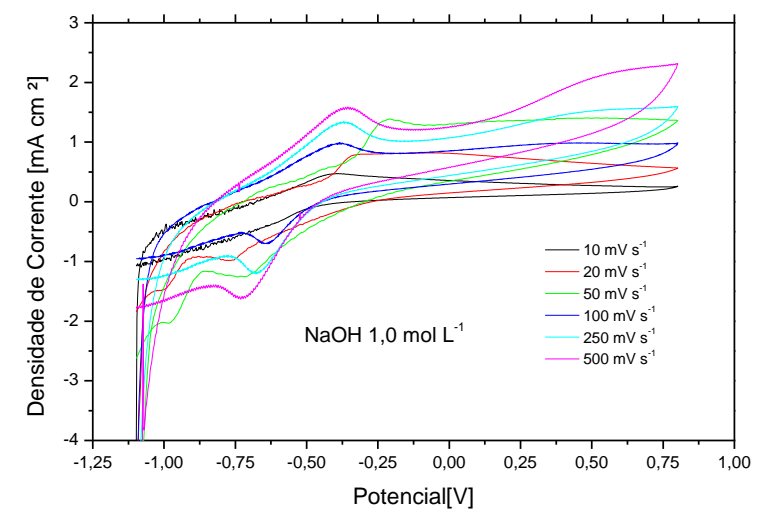

Figura 3: Voltamogramas para diferentes velocidade de varredura do sistema $\mathrm{Fe} / \mathrm{NaOH} 1,0 \mathrm{~mol} \mathrm{~L}^{-1}$.

Ainda em relação às Figuras 2 e 3, há que chamar a atenção para a presença de picos catódicos. Para o sistema $\mathrm{Fe} / \mathrm{NaOH} 0,10 \mathrm{~mol} \mathrm{~L}^{-1}$, nas velocidades de varredura $10,20,50$ e $100 \mathrm{mV} \mathrm{s}^{-1}$, há a presença de um único pico catódico nos voltamogramas. Já para a velocidade de varredura $250 \mathrm{mV} \mathrm{s}^{-1}$, há dois picos catódicos. Quanto ao sistema $\mathrm{Fe} / \mathrm{NaOH} 1,0 \mathrm{~mol} \mathrm{~L}^{-1}$, nas velocidades de varredura 10, 20, 50 e $100 \mathrm{mV} \mathrm{s}^{-1}$, há um pico catódico no voltamograma. Nas velocidades 250 e $500 \mathrm{mV} \mathrm{s}^{-1}$, há dois picos catódicos. Possível interpretação: para os casos com um único pico catódico, estaria ocorrendo a redução do filme de $\mathrm{Fe}(\mathrm{OH})_{2}$ a $\mathrm{Fe}$; nos casos com dois picos catódicos, o primeiro pico corresponderia à passagem de $\alpha-\mathrm{FeOOH}$ a $\mathrm{Fe}(\mathrm{OH})_{2}$ e o segundo pico seria redução de $\mathrm{Fe}(\mathrm{OH})_{2}$ a Fe.

\section{Conclusões}

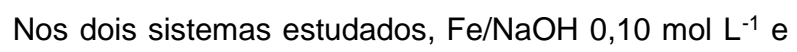
$\mathrm{Fe} / \mathrm{NaOH}$ 1,0 mol L-1., o voltamograma da medida de interesse não apresentou problemas devido a formação de bolhas de hidrogênio. Além disto, os voltamogramas tenderam a um perfil estacionário, sendo a diferença de carga anódica total das duas últimas varreduras de $3 \%$. Para as velocidades abaixo de $100 \mathrm{mV} \mathrm{s}^{-1}$, verificou-se, para ambos os sistemas estudados, que há a presença de um único pico anódico nos voltamogramas, o qual corresponderia à formação e crescimento de um filme de $\mathrm{Fe}(\mathrm{OH})_{2}$. Já para as velocidades acima de $100 \mathrm{mV}$ $\mathrm{s}^{-1}$, há dois picos anódicos, sendo o primeiro pico atribuído à formação e crescimento de um filme de $\mathrm{Fe}(\mathrm{OH})_{2}$ e o segundo à passagem de $\mathrm{Fe}(\mathrm{OH})_{2}$ a $\alpha-$
FeOOH. Também foram detectados nos voltamogramas a presença de picos catódicos. Para as velocidade até $100 \mathrm{mV} \mathrm{s}^{-1}$, para os dois sistemas estudados, observou-se a presença de um único pico catódico nos voltamogramas. Já para velocidades de varredura acima de $250 \mathrm{mV} \mathrm{s}^{-1}$, houve dois picos catódicos. A interpretação destes picos seria: para os casos com um único pico catódico, estaria ocorrendo a redução do filme de $\mathrm{Fe}(\mathrm{OH})_{2}$ a $\mathrm{Fe}$; nos casos com dois picos catódicos, o primeiro pico corresponderia à passagem de $\alpha-\mathrm{FeOOH}$ a $\mathrm{Fe}(\mathrm{OH})_{2}$ e o segundo pico seria redução de $\mathrm{Fe}(\mathrm{OH})_{2}$ a $\mathrm{Fe}$.

\section{Agradecimentos}

Um dos autores (J. G. Giori) agradece à UFES pelo financiamento da bolsa de Iniciação Científica.

\section{Referências}

[1] AMARAL, S. T.; MARTINI, E. M. A.; MÜLLER, I. L. Corrosion Science, v. 43, p. 853-879, 2001.

[2] MAURICE, V.; MARCUS, P. Electrochimica Acta, v. 84, p. 129-138, 2012.

[3] KURODA, K. et al. Journal of the Electrochemical Society, v. 129, p. 2163-2169, 1982.

[4] GOFF, A. et al. Journal of the Electrochemical Society, v. 137, p. 2684-2690, 1990.

[5] GUTIÉRREZ, C.; BEDEN, B. Journal of Electroanalytical Chemistry, v. 293, p. 253-259, 1990.

[6] TONEY, M. L. J. et al. Physical Review Letters, v. 79, p. 4282-4285, 1997.

[7] Xu, W. et al. Electrochimica Acta, v. 54, p. 57275738, 2009.

[8] SATO, N.; NODA, T.; KUDO, K. Electrochimica Acta, v. 19, p. 471-475, 1974.

[9] MacDONALD, D. D.; ROBERTS, B. Electrochimica Acta, v. 23, p. 781-786, 1978.

[10] OGURA, K. Electrochimica Acta, v. 25, p. 335-339, 1980.

[11] D'AlKAINE, C. V.; DA SILVA, J. M. Corrosion Science, v. 31, p. 661-666, 1990.

[12] MacDONALD, D. D. Electrochimica Acta, v. 56, p. 1761-1772, 2011. 